\title{
Synthesis of Dendritic Magnetic Graphene Oxide By Radical Polymerization As Adsorbent For Rapid Removal of Malachite Green From Aqueous Solutions
}

\author{
Seyyed Ali Razavikia \\ Islamic Azad University \\ Mehdi Faramarzi ( $\sim$ m.ff19850@gmail.com ) \\ Islamic Azad University \\ Seyed Aboutaleb Mousavi Parsa \\ Islamic Azad University \\ Hajir Karimi \\ Yasouj University
}

\section{Research Article}

Keywords: Magnetic graphene oxide, dendrimer, radical polymerization, malachite green, Nano adsorbent

Posted Date: November 17th, 2021

DOI: https://doi.org/10.21203/rs.3.rs-1079310/v1

License: (c) (i) This work is licensed under a Creative Commons Attribution 4.0 International License.

Read Full License 


\title{
Synthesis of Dendritic Magnetic graphene oxide by Radical polymerization as
}

\section{Adsorbent for Rapid Removal of Malachite green from Aqueous Solutions}

Seyyed Ali Razavikia ${ }^{1}$, Mehdi Faramarzi ${ }^{* 1,2}$, Seyed Aboutaleb Mousavi Parsa ${ }^{1}$, Hajir Karimi ${ }^{3}$

${ }^{1}$ Department of Chemical Engineering, Yasooj Branch, Islamic Azad University, Yasooj, Iran.

${ }^{1}$ Department of Chemical Engineering, Gachsaran Branch, Islamic Azad University, Gachsaran, Iran.

${ }^{3}$ Department of Chemical Engineering, Yasouj University, Yasouj, Iran.

\begin{abstract}
Disposal of Malachite green containing sewage from related industries has resulted in global concern. Thus, removing Malachite green from aqueous solutions is highly significant and necessary. during this study, magnetic graphene oxide coated with dendrimer (G (1) -MGOchitosan) was prepared successfully and applied for removing cationic malachite green in various conditions. The properties of the synthesized adsorbent (G (1) -MGO-chitosan) were evaluated using XRD, FTIR, BET, FESEM, TEM and TGA. Furthermore, the effect of different parameters on malachite green removal was studied. The results indicated that at $\mathrm{pH}=8$, temperature of 40 ${ }^{\circ} \mathrm{C}$, initial concentration $600 \mu \mathrm{g} \mathrm{mL}-1$ and contact time $10 \mathrm{~min}$ were obtained as optimal values for removing malachite green with nanoadsorbent (G (1) -MGO-chitosan) with maximum adsorption capacity of malachite green was obtained at $38.71 \mu \mathrm{g} \mathrm{mg}^{-1}$. The high correlation coefficient $\left(\mathrm{R}^{2}=\right.$ 0.9947) for the Freundlich model confirmed that the Freundlich model is appropriate for fitting laboratory data. Based on the model, Temkin heat adsorption for malachite green $\mathrm{j} \mathrm{mol}^{-1}$ is $\mathrm{B}=$ 8.1447, indicating that the process of dye adsorption with Nano adsorbent is of physical type.
\end{abstract}

Corresponding author: * Mehdi Faramarzi, Tel: +98-9177414562

E-mail address: faramarzi@iaug.ac.ir 
Based on the results of fitting the kinetic models of Malachite green adsorption by Nano adsorbent, $\mathrm{Hu}$ and McKay's model with higher correlation coefficient $\left(\mathrm{R}^{2}=0.9994\right)$ is more consistent with experimental data than other models. Since no large decrease is observed in Malachite green removal in seven consecutive recovery cycles, thus Nano adsorbent has a high stability and can be used several times.

Keywords: Magnetic graphene oxide, dendrimer, radical polymerization, malachite green, Nano adsorbent.

\section{Introduction}

Pollution of water resources because of the fast growth of world industry and economic activities has become a highly vital and high issue for the survival of humanity and other lives [1]. Dyes are extensively employed in industrial units like paper, paint, leather, textiles, pigments, cosmetics, artificial dyes, and plenty of other applications [2]. Most reactive dyes are toxic and have the danger of teratogenic and carcinogenic mutations [2]. The existence of such dyes in water may increase the danger of cancer, skin irritation, and respiratory problems in humans [2]. it's been currently estimated that over 100000 commercial dyes are available, and therefore the production is about 700000 to 1000000 tons p.a. [3]. Nevertheless, the presence of dyes even in low concentrations damages the aesthetic nature of the environment. Dyes may cause serious harm to humans. When dyes reach beverage, studies have indicated that carcinogenicity is linked to certain sorts of intermediates or metabolites like Benzedrine [4]. Malachite green (MG), a base dye of Nmethyl diamine tri-phenylmethane, is extensively utilized in the dyeing of the leather, silk, paper, and textile industries and is even employed in different aquaculture industries round the world its high efficacy against bactericides and fungicides [5]. Nevertheless, MG is extremely toxic to animals, plants, and humans thanks to its mutagenizing and carcinogenicity [6]. Removing dyes is 
more significant in controlling the environmental pollution as dyes not only cause serious environmental problems, but also create a significant public health concern [4]. Furthermore, the discharge of dyes without filtration into rivers is another factor since the dyes are highly visible and harmful to aquatic animals [7].

In addition, several groups of dyes are the stable molecules which are proof against decomposition by light, chemicals, biology, and other factors and are considered as mutagenic for human. Most dyes are complex organic molecules which require resistance to external factors like detergents [9]. Thus, it's necessary that sewage contaminated with different colors should be treated in an appropriate manner before release into the environment [9]. So far, plenty of methods are presented for the effective removal of hazardous substances from aqueous solutions like biological, physical methods, electrical coagulation, chemical, photocatalytic decomposition, oxidation, etc. [10]. Among the suggested techniques, adsorption is an appropriate method which has provided good results because it is efficient, simple, and cost-effective [11]. Therefore, this issue has made researchers to seem for a few adsorbents with high accessibility and cost-effectiveness. Nowadays, large volumes of low-cost adsorbents are studied including common adsorbents, agricultural and industrial products like atomic number 6 [12], carbon nanotubes [13], activated slag, sugarcane, wood dust, fruit bark [14], tea waste ash, rice husk [15], and metal-organic framework [16]. Nevertheless, there's still a good need for exploring and discovering affordable and new adsorbents with high adsorption capacity, high selectivity, and short contact time for color adsorption [17]. in a very study [18], rambutan peel fixed on carbon was used for removing malachite green dye. The researchers studied the consequences of various parameters like initial malachite green concentration, contact time, solution temperature and initial $\mathrm{pH}$ on the removal of malachite green dye. The results indicated that the removal of green property increases with increasing the contact 
time and temperature of the answer. The adsorption equilibrium data with the Freundlich model indicated the most effective performance and also the adsorption kinetics followed the secondorder synthetics. In another study [19], gold nanoparticles stabilized on carbon were used for removing thiazine dye. The results indicated the isotherm model and so revealed that the Langmuir model had the simplest fit. additionally, different synthetic models were evaluated by analyzing the experimental data. After the analysis, it had been found that the adsorption kinetics follow the quasi-second-order synthetics. additionally, it indicated 95\% removal of dye in an exceedingly short time of 1.6 minutes with $0.01 \mathrm{~g}$ of adsorbent.

In all cases, the magnetic adsorbents were easily separated from the answer using an external magnet. Recycling experiments indicated that the removal efficiency of MB after 10 adsorption cycles still remained high. In general, $\mathrm{MgFe}_{2} \mathrm{O}_{4} @ \mathrm{SiO}_{2} \mathrm{NPs}$ were identified as efficient, selective, and reusable adsorbents for removing MB. during a study [21], water-stable graphene oxide composite (ZIF-67 @ GO) was used for removing malachite green dye from water. The results indicated that the adsorption data with $\mathrm{R}^{2}=0.9999$ follow the Freundlich model. The removal efficiency reduces by only $6 \%$ after different cycles. The nanoadsorbent was prepared from the synthesis of magnetic graphene oxide coated with dendrimer (G (1) -MGO-chitosan). The synthesized adsorbent properties are assessed using XRD, FTIR, BET, FESEM, TEM and TGA. Adsorption efficiency is estimated using acetone and malachite green dye under the Effect of concentration, time, temperature, $\mathrm{pH}$ and reusability. Furthermore, the kinetics, isotherm modeling and thermodynamics of the adsorption process are considered.

\section{Materials and method}

\subsection{Equipment}


Graphene oxide (GO), ammonia $\left(\mathrm{NH}_{3}\right.$ ), ethylene diamine (EDA), n-hydroxy succinimide (NHS), 1-ethyl-3- (3-dimethylaminopropyl) carbodimide (EDC), hydroxide $(\mathrm{NaOH})$, acid $(\mathrm{HCl})$, mercaptoacetic acid (MAA), allylamine, Azobisisobutyronitrile (AIBN), chitosan, methyl acrylate (MA), ethanol (99\%), acetone and malachite green dye (MG) $\left(\mathrm{C}_{52} \mathrm{H}_{54} \mathrm{~N}_{4012}\right)$ were prepared from Merck Company, Germany. All of the used solutions are prepared to the desirable concentration by diluting the stock solution with $\mathrm{H}_{2} \mathrm{O}$. diffraction (XRD) patterns with Philips PW1730 XRD diffraction device, diffusion scanning microscope (FESEM) on Hitachi S-4160, BET area analysis device (BET specific area analysis) and JW-BK132 pore size, Pyris Diamond thermometry / differential thermal analyzer, VSM (Vibrating sample magnetometer) with MDKB, TEM Philips EM 208S analyzer, FTIR adsorption spectrum fir selected samples, Shimadzu FT-IR-8300 spectrometer, and UV-DRS spectrum were used with JASCO V-670 spectrophotometer.

\subsection{Preparation of magnetic graphene oxide (MGO)}

Graphene oxide (GO) was prepared per the procedure published within the literature $[1,2]$. Magnetic graphene oxide was prepared by co-precipitation method [3]. Briefly, $\mathrm{FeCl}_{2} \cdot 4 \mathrm{H}_{2} \mathrm{O}(1.35$ g, $6.8 \mathrm{mmole}), \mathrm{FeCl} 3 \cdot 6 \mathrm{H}_{2} \mathrm{O}(3.68 \mathrm{~g}, 13.6 \mathrm{mmole})$ and $\mathrm{GO}(1 \mathrm{~g})$ were mixed in $100 \mathrm{~mL}$ of deionized water under $\mathrm{N}_{2}$ atmosphere with vigorous stirring at temperature for $30 \mathrm{~min}$. The mixture was then heated to $85{ }^{\circ} \mathrm{C}$ and $100 \mathrm{~mL}$ of ammonia solution (25\%) was added drop wisely for two h. The resulting MGO composite was magnetically separated and washed several times with deionized water and ethanol.

\subsection{Conjugation of Ethylenediamine (EDA) to the MGO}

EDA conjugation to the MGO was accomplished through an acidification reaction among the amine groups of EDA and also the acid group on the MGO surface. First, to $50 \mathrm{~mL}$ of twenty-two (w/v) MGO solution in deionized water, N-Hydroxysuccinimide (NHS) (23 mg, $0.2 \mathrm{mmol}$ ) and 1- 
Ethyl-3-(3-dimethylaminopropyl) carbodiimide (EDC) (31 mg, $0.2 \mathrm{mmol})$ were added and stirred at $25^{\circ} \mathrm{C}$ for $2 \mathrm{~h}$ so as to activate the carboxyl groups of MGO. The $\mathrm{pH}$ of solution was adjusted to eight using hydrated oxide $(1 \mathrm{M})$ and was mixed with EDA $(0.2 \mathrm{mmol})$, stirred at $40{ }^{\circ} \mathrm{C}$ for twentyfour $\mathrm{h}$. The resulting MGO-NH 2 particles were separated magnetically and washed with deionized water $(5 \mathrm{x})$ before drying in vacuum.

\subsection{Conjugation of mercaptoacetic acid (MAA) to the MGO-NH2}

MAA as chain agency for radical polymerization, was conjugated to $\mathrm{MGO}-\mathrm{NH}_{2}$ using acidification reaction. First, to $50 \mathrm{~mL}$ of fifty (v/v) MAA solution in anhydrous DMSO, EDC (31 $\mathrm{mg}, 0.2 \mathrm{mmol}$ ) and NHS (23 mg, $0.2 \mathrm{mmol})$ were added and stirred at $25{ }^{\circ} \mathrm{C}$ for two h. Then, a suspension of MGO-NH2 (3 $\mathrm{g}$ dispersed in $30 \mathrm{~mL}$ of anhydrous DMSO) was added to the answer and therefore the mixture was stirred at $25^{\circ} \mathrm{C}$ for five days. The resulting product (MGO-MAA) was separated magnetically then washed with DMSO, deionized water and acetone, and dried at vacuum at temperature.

\subsection{Radical polymerization}

Allylamine was grafted onto MGO-MAA particles using radical polymerization. $1 \mathrm{~g}$ of MGOMAA particles and $15 \mathrm{~mL}$ of Allylamine and $0.1 \mathrm{~g}$ of Azobis isobutyronitrile (AIBN) as an initiator were stirred under the $\mathrm{N}_{2}$ atmosphere in ethanol medium $(30 \mathrm{~mL})$ at $50{ }^{\circ} \mathrm{C}$ for twenty-four $\mathrm{h}$. The resulting Allylamine-g-MGO particles were magnetically separated and washed with $20 \mathrm{~mL}$ of deionized water and ethanol, so dried at $50^{\circ} \mathrm{C}$ in vacuum.

\subsection{Grafting of chitosan dendrimer on Allylamine-g-MGO}

Final step of modification was performed through Micheal type addition with chitosan. 1g of Allylamine-g-MGO and three.1 mL of methyl acrylate (MA) were stirred under the $\mathrm{N} 2$ atmosphere in anhydrous methanol $(30 \mathrm{ml})$ at $50{ }^{\circ} \mathrm{C}$ for 3 days. Upon reaching ambient temperature, magnetic 
separation of the particles passed off, they were washed with anhydrous methanol (20 mL, 3x), and were then dried under a vacuum for on a daily basis, thus producing $G(0.5)$. The obtained powder was then added to chitosan $(100 \mathrm{mg})$ in dry methanol $(30 \mathrm{ml})$ and stirred under $\mathrm{N}_{2}$ at 50 ${ }^{\circ} \mathrm{C}$ for five days. Again, magnetic separation of the particles was completed, they were washed with methanol (dry, 3x), so finally, under vacuum, were dried thus producing G (1)-MGOchitosan.

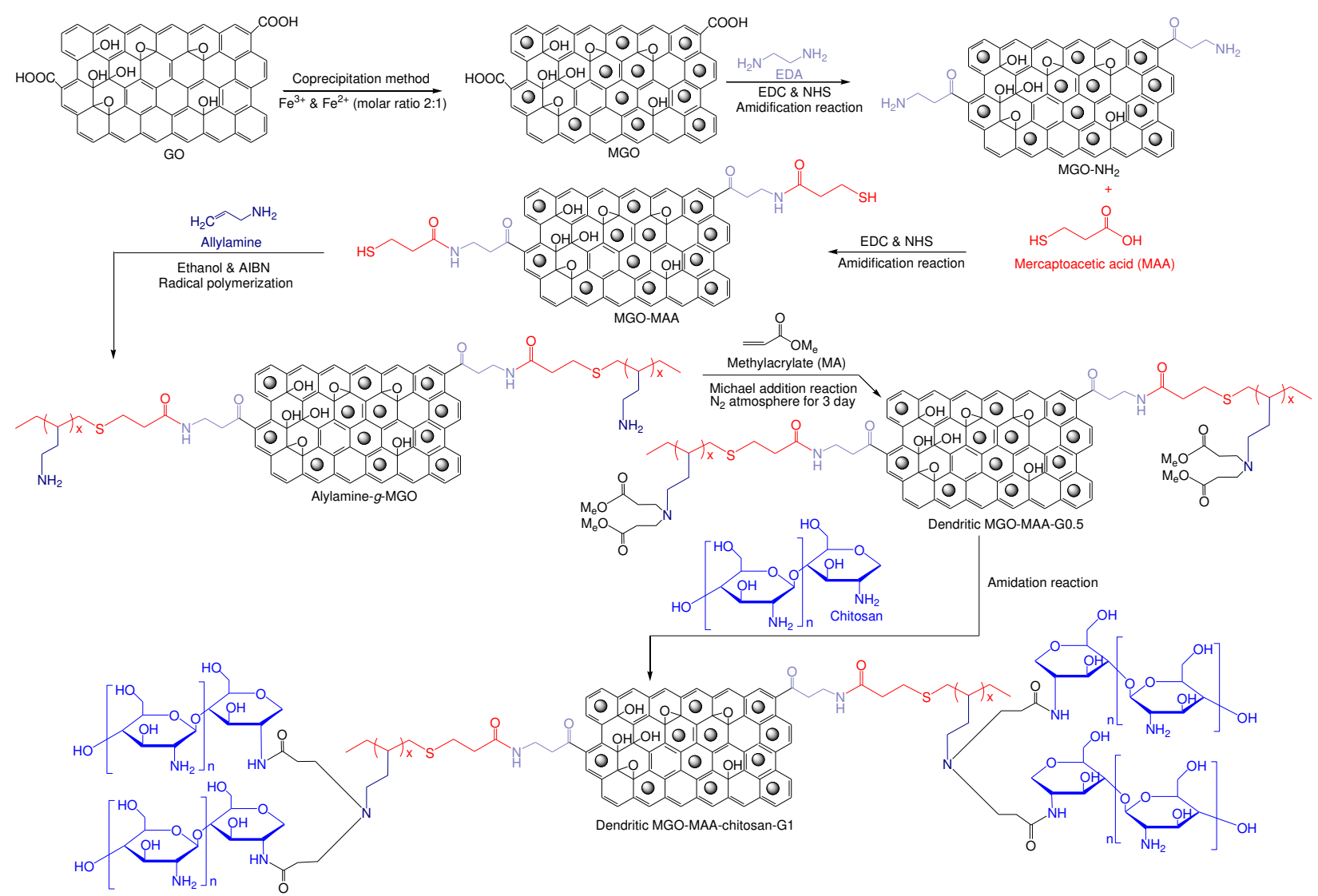

Fig.1. Synthesis scheme for the of G (1)-MGO-chitosan.

\subsection{Optimization of adsorption conditions}

The process of Malachite green adsorption by Nano adsorbent using adsorption method is stricken by the parameters like solution $\mathrm{pH}$, contact time, and temperature. additionally, the quantity of dye concentration is one among the factors affecting the adsorption rate because of the connection between the active sites of the adsorbent surface for adsorption. In other words, Nano adsorbent 
has the simplest performance at a $\mathrm{pH}$, temperature, contact time, and a selected concentration of dye.

Thus, optimizing the Malachite green adsorption conditions is of great significance. so as to perform the tests, $50 \mathrm{~mL}$ of dye solution was added to variety of test tubes consistent with the optimization conditions so placed inside a thermal shaker.

At the tip of the test time, the liquid phase was separated from the magnetic Nano adsorbent at each step employing a 1.3 Tesla magnet to be ready for determining the quantity of dye which wasn't adsorbed by the atomic adsorbent. the quantity of adsorbed dye per milligram of Nano adsorbent is obtained from the subsequent Eq. (1):

$\mathrm{q}_{\mathrm{e}}=\left(\mathrm{C}_{\mathrm{i}}-\mathrm{C}_{\mathrm{e}}\right) \frac{\mathrm{V}}{\mathrm{M}}$

$\mathrm{n}$ which qe $\left(\mu \mathrm{g} \mathrm{mg}^{-1}\right)$ is that the amount of adsorbed dye per milligram of adsorbent. $\mathrm{Ci}$ and $\mathrm{Ce}$ represent the initial dye concentrations and therefore the concentration of unabsorbed dye in terms of $\mu \mathrm{g} \mathrm{mL}^{-1}$ within the liquid phase, respectively. $\mathrm{V}$ refers to the degree of the liquid innovate terms of $\mathrm{mL}$ and $\mathrm{M}$ is that the Nano adsorbent mass employed in terms of $\mathrm{mg}$.

In order to review the dye adsorption mechanism on Nano adsorbent, the experimental data of qe and Ce were evaluated with the isotherms of Freundlich, Langmuir [22], Temkin and DubininRadushkevich. The Langmuir and Freundlich isotherms Eq. (2) and Eq. (3):

$$
\begin{aligned}
& \mathrm{q}_{\mathrm{e}}=\frac{\mathrm{q}_{\mathrm{m}} \mathrm{k}_{\mathrm{L}} \mathrm{C}_{\mathrm{e}}}{1+\mathrm{k}_{\mathrm{L}} \mathrm{C}_{\mathrm{e}}} \\
& \mathrm{q}_{\mathrm{e}}=\mathrm{k}_{\mathrm{F}} \mathrm{C}_{\mathrm{e}}{ }^{1 / \mathrm{n}}
\end{aligned}
$$

In the isotherm equations qe $\left(\mu \mathrm{g} \mathrm{mg}^{-1}\right)$ represents the quantity of dye adsorbed per milligram of Nano adsorbent and Ce $\left(\mu \mathrm{g} \mathrm{mL}^{-1}\right)$ represent the concentration of unabsorbed dye. within the Langmuir model, $\mathrm{qm}\left(\mu \mathrm{g} \mathrm{m}^{-1}\right)$ represents the utmost adsorption capacity and $\mathrm{kL}$ shows the

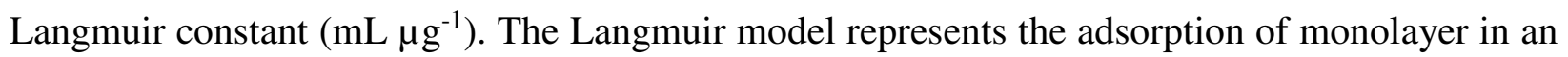


exceedingly homogeneous system. In relevance the Langmuir isotherm, the separation factor (RL) is raised which is decided by the Eq. (4):

$$
\mathrm{R}_{\mathrm{L}}=\frac{1}{1+\mathrm{k}_{\mathrm{L}} \mathrm{C}_{\mathrm{i}}}
$$

The value of the separation factor will be analyzed by three intervals: $R L=0$ implies that the adsorption reaction is reversible. $\mathrm{RL}=1$ means linear adsorption, $1>\mathrm{RL}>0$ means optimal adsorption, and RL $>1$ isn't the optimal adsorption process [22]. within the Freundlich modelm kF indicates the constant coefficient in terms of $\left[\left(\mu \mathrm{g} \mathrm{mg} \mathrm{g}^{-1}\right)(\mathrm{L} \mu \mathrm{g})\right]$ and $1 / \mathrm{n}$ and $1 / \mathrm{n}$ shows the heterogeneity factor and also the adsorption intensity. If $1 / \mathrm{n}=1$, the adsorption process is linear. If $0<1 / \mathrm{n}<1$, adsorption is perfect. additionally, $1 / \mathrm{n}<1$ means the method of adsorption is chemical. Furthermore, $1 / \mathrm{n}<1$ implies that the adsorption process physical. Freundlich model shows the multi-layer adsorption (Creating heterogeneous surface bonds) to the heterogeneous system. in step with the speculation of Temkin, adsorption is monolayer and adsorption places are equal in terms of energy [23]. The Temkin model is defined by the Eq. (5):

$\mathrm{q}_{\mathrm{e}}=\mathrm{A}+\mathrm{BlnC}_{\mathrm{e}}$

The Temkin constants are $\mathrm{A}=\mathrm{B} \operatorname{lnkT}$ and $\mathrm{B}=\mathrm{RT} / \mathrm{bT}$, where $\mathrm{kT}$ relies on $(\mathrm{mL} \mathrm{mg}-1)$ and $\mathrm{B}$ is dimensionless. additionally, $\mathrm{T}$ represents the temperature in Kelvin, $\mathrm{j}$ mol-1K-1 $\mathrm{R}=8.314$ represents the final constant of gas and bT indicates the warmth of dye adsorption in terms of $\left(\mathrm{jmol}^{-1}\right)$. If the worth of bT is a smaller amount than $\mathrm{j} \mathrm{mol}^{-1}=40$, the adsorption is of physical type [23]. so as to work out the physical or chemical nature of the adsorption process, the DubininRadushkevich isotherm [24] is Eq. (6):

$$
\mathrm{q}_{\mathrm{e}}=\mathrm{q}_{\mathrm{m}} \mathrm{e}^{-\mathrm{h} \varepsilon^{2}}
$$

In this regard, qe represents the number of dye adsorbed on the Nano adsorbent in micrograms per milligram, qm represents the utmost adsorption capacity in micrograms per milligram and constant 
$\mathrm{h}$ is expounded to the adsorption energy in terms of Mole squared by Joule squared. additionally, $\varepsilon$ represents the plan potential in terms of Joule squared to Mole squared which is set using the Eq. (7):

$\varepsilon=\mathrm{RT} \ln \left(1+\frac{1}{\mathrm{C}_{\mathrm{e}}}\right)$

In this equation, $\mathrm{R}$ represents the final constant of gases adequate to $8.314 \mathrm{jmol}^{-1} \mathrm{~K}^{-1}$, T represents the temperature in Kelvin and Ce represents the concentration of non-adsorbed dye in terms of ( $\mu \mathrm{g}$ $\left.\mathrm{mL}^{-1}\right)$. the common free energy of dye adsorption (E) is set through the worth of $\mathrm{h}$ obtained from Eq. (7) supported the Eq. (8) [25]:

$\mathrm{E}=\frac{1}{\sqrt{-2 \mathrm{~h}}}$

The nature of adsorption is realized using the worth of $\mathrm{E}$. If the worth of $\mathrm{E}$ is $8-16 \mathrm{~kJ} / \mathrm{mol}$, the character of adsorption is chemical, and if it's but $8 \mathrm{~kJ} / \mathrm{mol}$, it'll be physical adsorption.

In order to check the adsorption kinetics of Lagergren [26], Hu and McKee [27] models, the interparticle diffusion [28] and Elovich [29] are obtained from the experimental data qe and t achieved from the Eq. (9) to Eq. (12):

$$
\begin{aligned}
& \mathrm{q}_{\mathrm{t}}=\mathrm{q}_{\mathrm{e}}\left(1-\mathrm{e}^{-\mathrm{kt}}\right) \\
& \mathrm{q}_{\mathrm{t}}=\frac{\mathrm{kq}_{\mathrm{e}}^{2} \mathrm{t}}{1+\mathrm{q}_{\mathrm{e}} \mathrm{kt}} \\
& \mathrm{q}_{\mathrm{t}}=\mathrm{C}+\mathrm{kt}^{1 / 2} \\
& \mathrm{q}_{\mathrm{t}}=\alpha+\beta \ln \mathrm{t}
\end{aligned}
$$

In the above-mentioned equations, qt represents the number of dye adsorbed by the Nano adsorbent at time $t$ in milligrams per gram, qe represents the adsorption capacity of the Nano adsorbent at equilibrium, $\mathrm{C}$ shows the $\mathrm{y}$-intercept, and $\mathrm{k}$ shows the rate constant. the speed constant of the Lagergren model is in min-1. the speed constant of $\mathrm{Hu}$ et al. Model is in $\mu \mathrm{g} \mathrm{mg}^{-1} \mathrm{~min}^{-1}$. 
In Elovich model, we have $\alpha=\left(\frac{1}{Q}\right) \ln (P Q)$ and $\beta=(1 / Q)$ where $P$ represents the initial adsorption rate in terms of $\mu \mathrm{g} \mathrm{mg}^{-1} \mathrm{~min}^{-1}$ and $\mathrm{Q}$ represents the desorption constant in $\left(\mathrm{mg} \mathrm{gg}^{-1}\right)$. The adsorption rate increases as the $\mathrm{P}$ value increases and the $\mathrm{Q}$ value decreases.

Experiments of Kinetics at temperature, $\mathrm{pH}$, and optimal concentration are studied for 60 minutes. Accordingly, the thermodynamic parameters of the adsorption process can be obtained. Gibbs free energy $(\Delta \mathrm{G})$ from the Eq. (13) [30]:

$\Delta \mathrm{G}=-\mathrm{RT} \ln \mathrm{K}$

In which $\mathrm{K}$ represents the Langmuir model constant or distribution coefficient, indicating the thermodynamic equilibrium constant. $\mathrm{R}$ shows the general constant of gases and $\mathrm{T}$ implies the temperature. On the other hand, Gibbs free energy is related to enthalpy $(\Delta \mathrm{H})$ and entropy $(\Delta \mathrm{S})$ by the Eq. (14):

$\Delta \mathrm{G}=\Delta \mathrm{H}-\mathrm{T} \Delta \mathrm{S}$

From the combination of equations (13) and (14), the Van 't Hoff equation is obtained as Eq. (15):

$$
\ln \mathrm{K}=\frac{\Delta \mathrm{S}}{\mathrm{R}}-\frac{\Delta \mathrm{H}}{\mathrm{RT}}
$$

Thus, the enthalpy and entropy of adsorption can be obtained using the slope and y-intercept ln K in terms of $1 / \mathrm{T}$, respectively. The results obtained from this section are presented in the next chapter.

\subsection{Reusability of the adsorbent}

The efficiency of Nano adsorbent in Reusability and reuse was evaluated with 7 consecutive adsorption-desorption cycles. After each cycle, the adsorbent was washed fully with deionized water for neutralizing and preparing the samples for adsorption in subsequent cycles. for every 
cycle, the dye was adsorbed under optimal conditions. The reusability of the adsorbent was investigated through successive dye adsorption cycles in optimal laboratory conditions.

\section{Results and discussion}

\subsection{Properties of Nano adsorbent}

The FTIR technique was used for determining the functional groups within the synthesized Nano adsorbent. As indicated in Fig. (2), it absolutely was found that the precise peaks associated with methylated carboxy at the range of $3448.39 \mathrm{~cm}-1$ and $1579 \mathrm{~cm}^{-1}$, are attributed to the hydroxyl and carboxylate (asymmetric tensile) groups, respectively [31]. The $1513 \mathrm{~cm}^{-1}$ and $1452 \mathrm{~cm}^{-1}$ tensile bond belong to the aromatic loops, and also the peaks appearing at the wavelength of $1739.19 \mathrm{~cm}^{-}$

${ }^{1}$ are attributed to the $\mathrm{C}=\mathrm{O}$ of the carbonyl groups in graphene oxide. the height $1092 \mathrm{~cm}^{-1}$ belongs to the O-C-O group within the structure of graphene oxide [32]. additionally, the adsorption peak of amino iron oxide nanoparticles at $526 \mathrm{~cm}^{-1}$ is related to the tensile vibration of the $\mathrm{Fe}-\mathrm{O}$ bond and therefore the strong adsorption peaks at $1216 \mathrm{~cm}^{-1}$ are the results of the vibrations of allylamine bond [33]. 


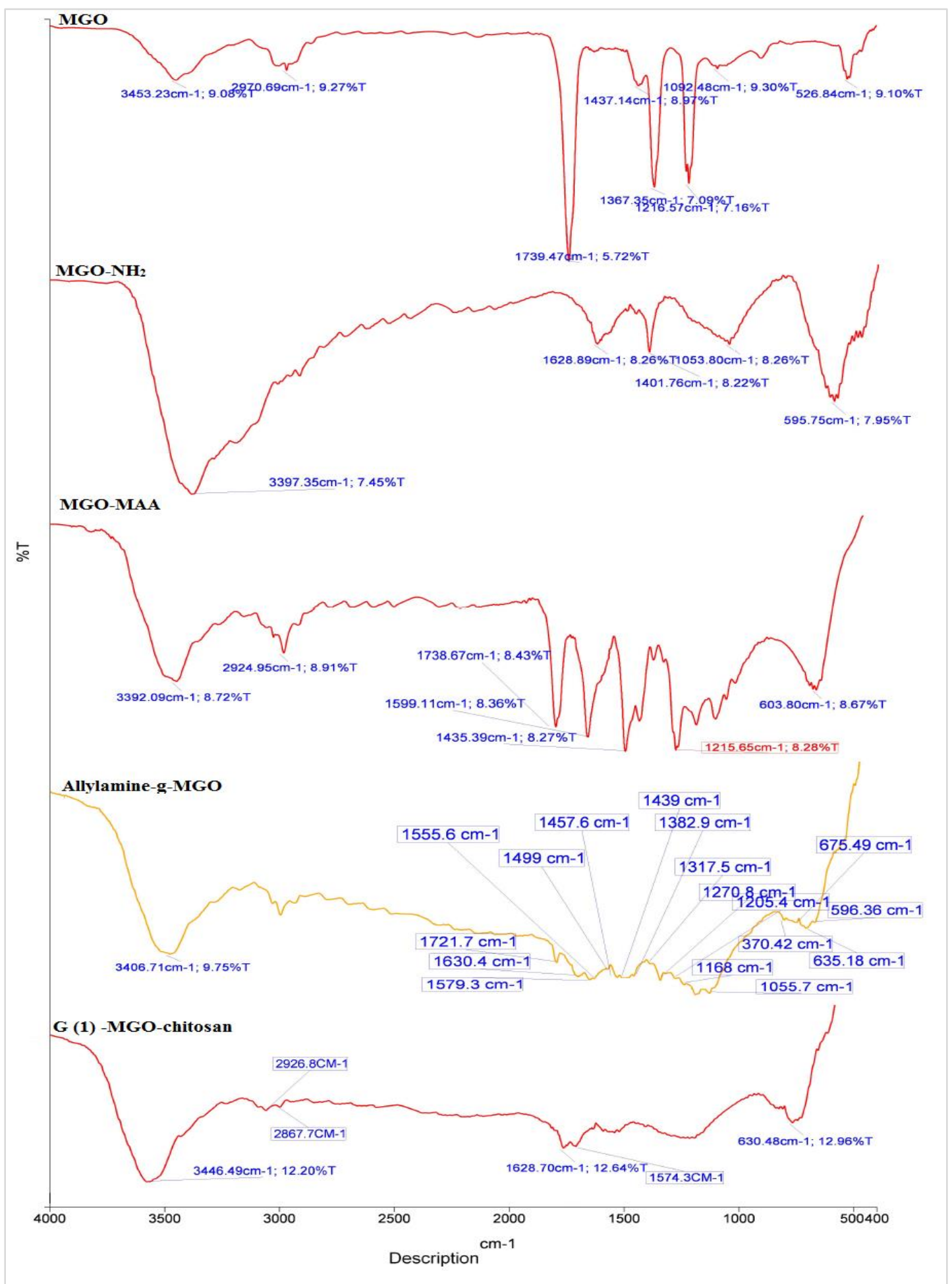

Fig. 2: FTIR spectrum of Nano adsorbent.

Fig. 3 indicates the BET analysis. The BET analysis was used for measuring the particular area and porosity of the synthesized Nano adsorbent. The results indicate that the realm is about 22.24 
$\mathrm{m} 2$. BET analysis indicate that the inter-area volume the full pore volume, and therefore the surface $19.501 \mathrm{~cm}^{2} \mathrm{gr}^{-1}, 0.2644 \mathrm{~cm}^{2} \mathrm{gr}^{-1}, 84.878 \mathrm{~m}^{2} \mathrm{~g}$. supported the analysis, the common diameter of pores in Nano adsorbent is $12.462 \mathrm{~nm}$. Thus, since the common diameter of Nano adsorbent pores is a smaller amount than $50 \mathrm{~nm}$, most of the observed pores are of the mesoporous type. Thus, the adsorption of dye molecules on the Nano adsorbent surface synthesized in solution increases due to high surface contact points [34].

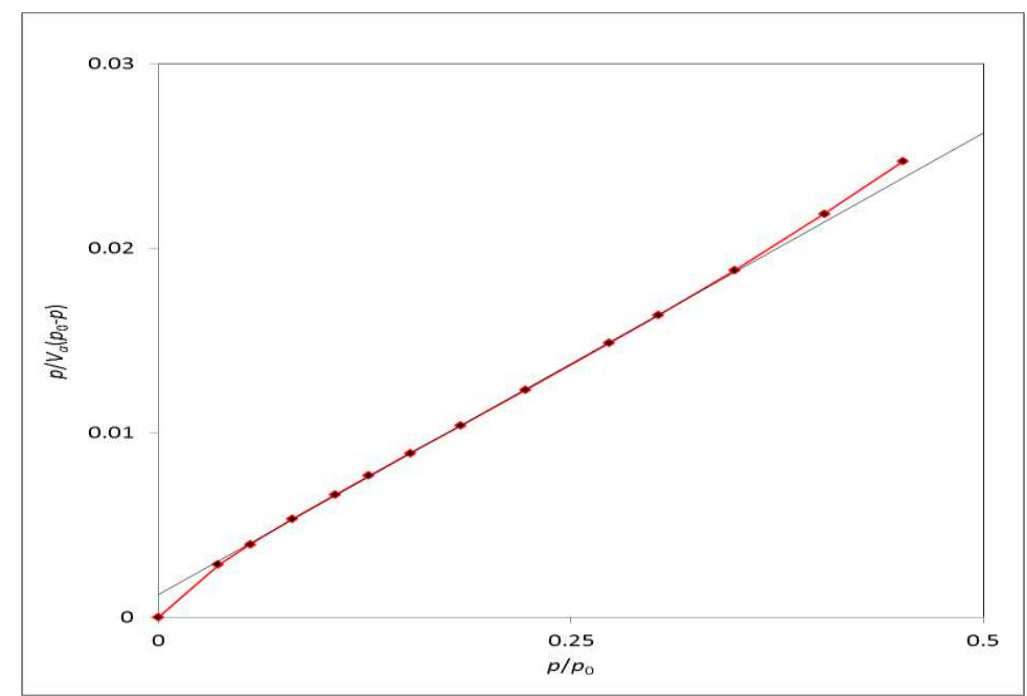

Fig. (3): BET analysis

The adsorption/desorption isotherms of $\mathrm{N}_{2}$ and the pore size distribution are displayed in Fig. 4. As can be observed, the adsorption and desorption isotherms of $\mathrm{N}_{2}$ are of IV type with hysteresis loops, which are mostly attributed to inter-pore materials according to the IUPAC classification [35]. From these results, the pore volume and specific surface area were measured to be 0.2644 $\mathrm{cm}^{3} \mathrm{~g}^{-1}$ and $84.878 \mathrm{~m}^{2} \mathrm{~g}$. 


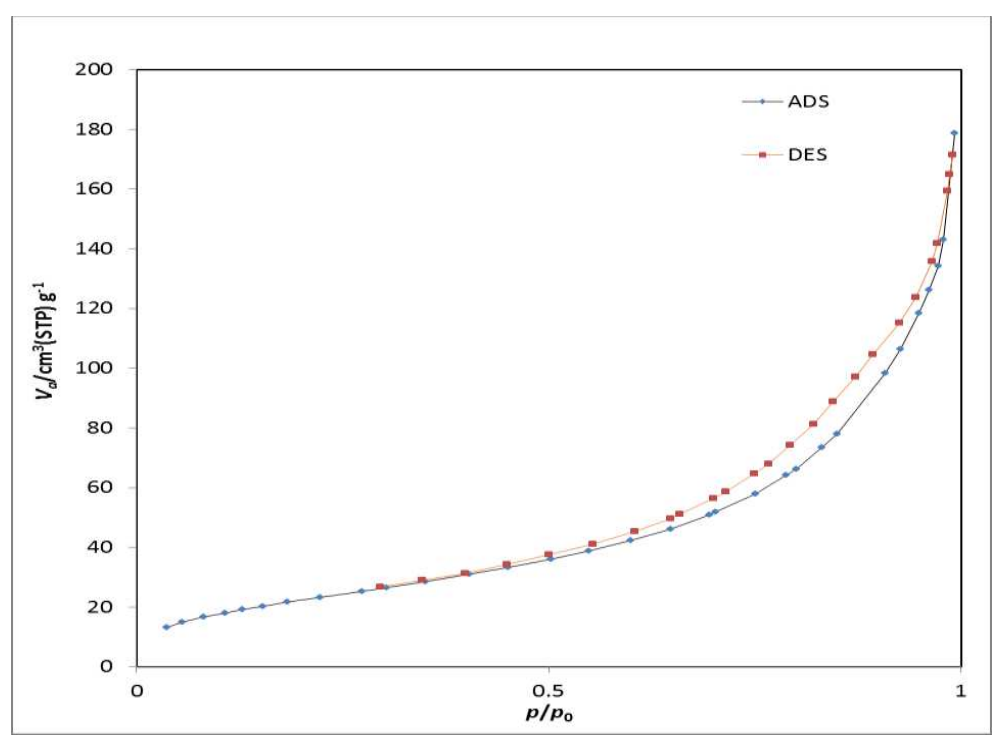

Fig. (4): $\mathrm{N}_{2}$ adsorption /desorption isotherms

In order to research the pore size distribution, the results of $\mathrm{BJH}$ analysis are presented in Fig. 5. This figure indicates that the synthesized adsorbents mainly contain meso-pore structures [36]. The structural properties of the synthesized adsorbent, including specific expanse, total pore volume, and pore diameter were obtained at $96.674 \mathrm{~m}^{2} \mathrm{~g}^{-1}, 0.266 \mathrm{~cm}^{3}$, and $1.64 \mathrm{~nm}$.

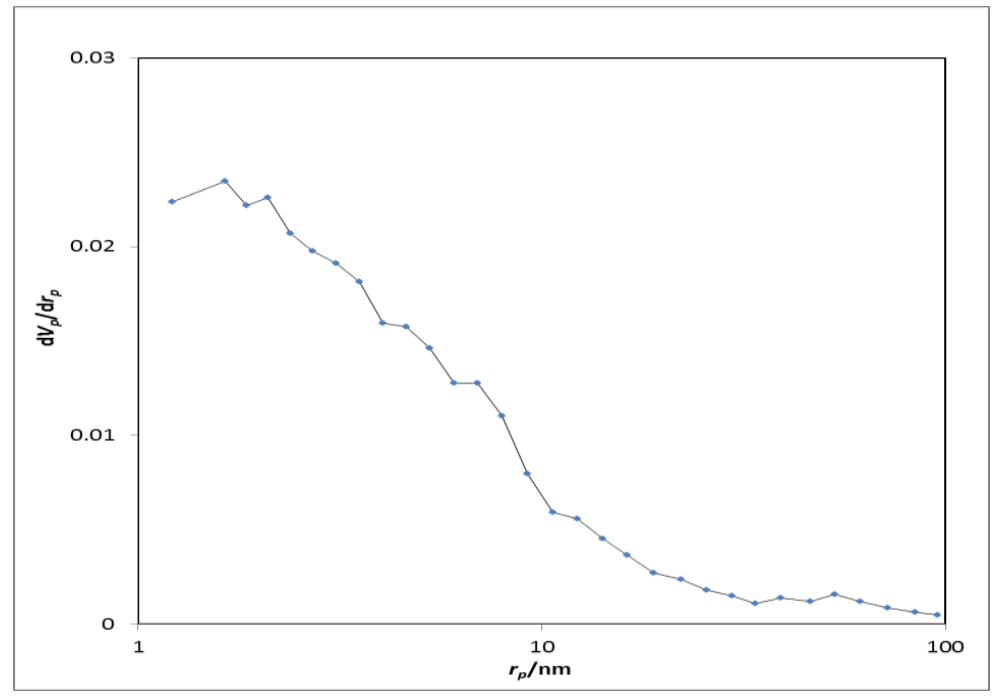

Fig. (5): BJH analysis

The magnetic properties of the synthesized adsorbent (G (1) -MGO-chitosan) were measured using VSM at temperature and also the magnetic hysteresis residue loops were obtained within the type of an S-shaped curve, as displayed in Fig. 6. The synthesized adsorbent magnetization (MS) (G 
(1) -MGO-chitosan) was found at $22 \mathrm{emug}^{-1}$, which is adequate for magnetic particle separation [37]. Thus, the synthesized adsorbent of the synthesized adsorbent (G (1) -MGO-chitosan) are often effective for color filtration employing a flux from water.

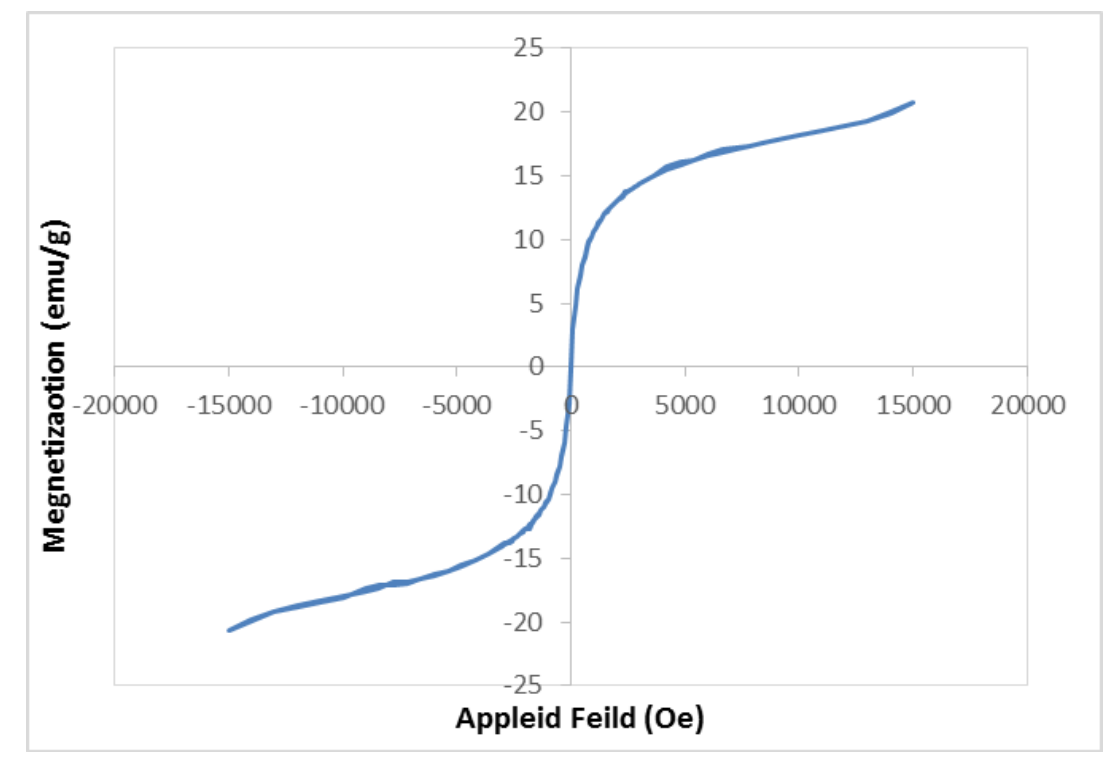

Fig. (6): VSM analysis

It should be noted that XRD analysis is said to Nano adsorbent and displayed in Fig. 7. As is observed, crystalline phases are ideal at peaks of $41,38,58$ and 77 , confirming the crystalline properties of the fabric. Thus, the presence of magnetic iron oxide nanoparticles reduced the intensity of the peaks so peaks 26 and 41 are associated with the presence of iron oxide nanoparticles within the synthesized Nano adsorbent. The magnetic property of Nano adsorbent has caused the loss of some peaks. the rationale is also that the atoms easily move in specific crystalline directions to make a regular crystal structure when magnetic crystals are formed within the absence of a flux. As shown in Fig. 5, fewer and wider peaks were revealed, indicating the formation of an amorphous material and therefore the consequent successful modification of the adsorbent [38]. 


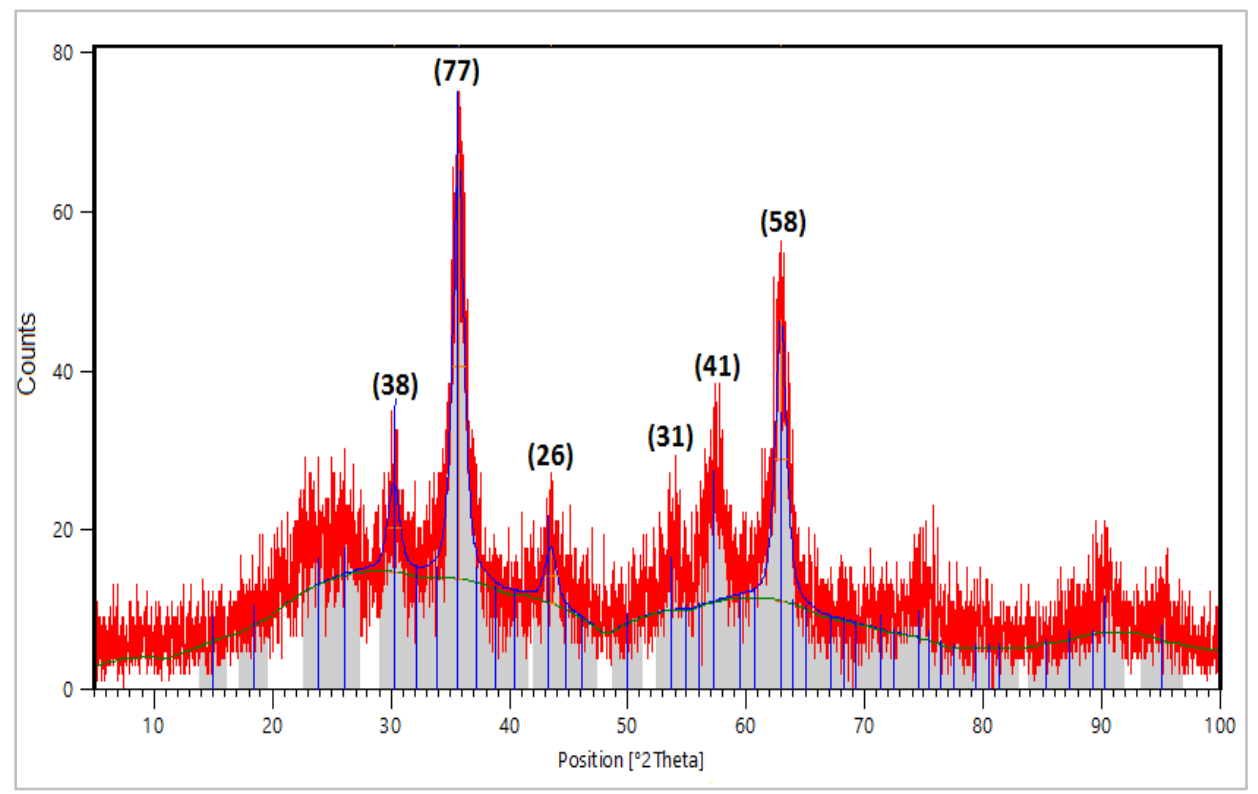

Fig. (7): XRD adsorbent analysis

Fig. 8 indicates the SEM images of the synthesized adsorbent. supported the pictures, the synthesized adsorbent particles have a heterogeneous and irregular structure. additionally, the synthesized adsorbent particles are within the sort of agglomerates and lumps [39]. Furthermore, the common diameter of the synthesized adsorbent is a smaller amount than $50 \mathrm{~nm}$ in keeping with SEM images (images recorded with scanning microscopy (FESEM).

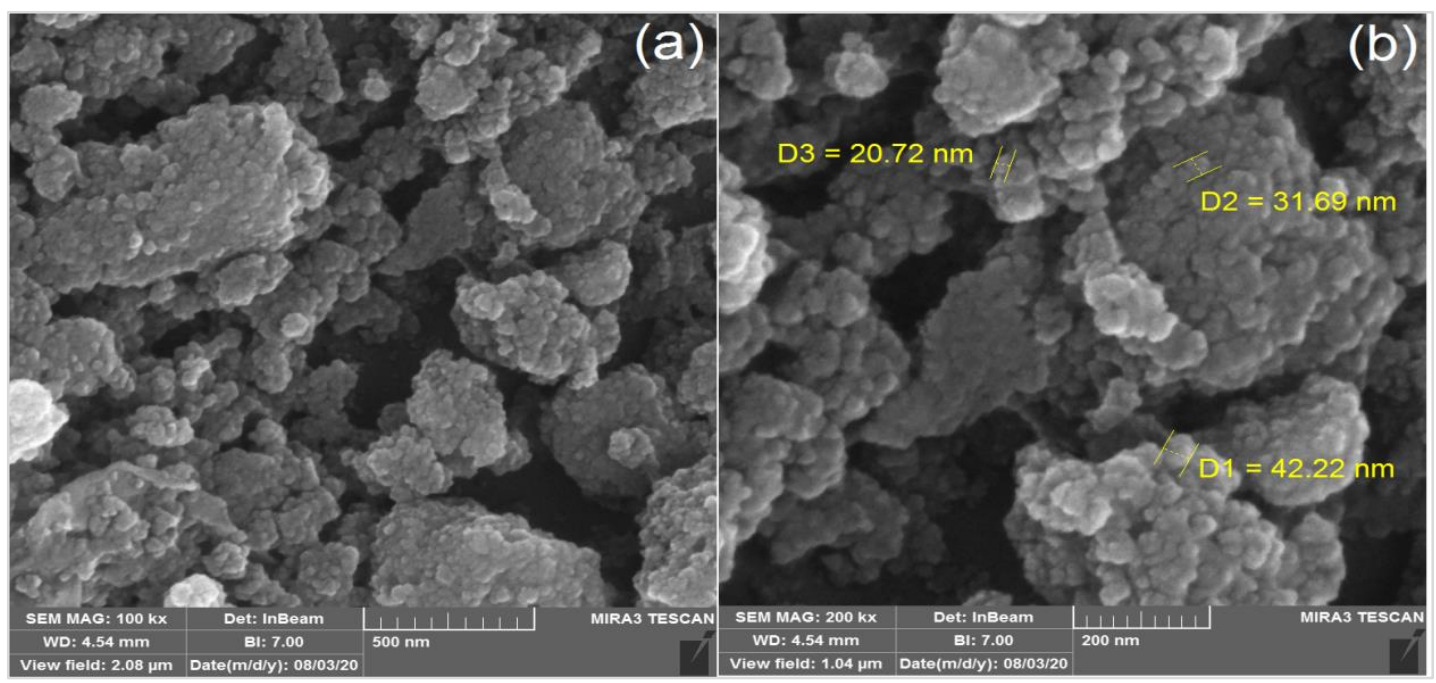

Fig. (8): Nano adsorbent SEM image with a magnification of a) $500 \mathrm{~nm}$ and b) $200 \mathrm{~nm}$ 
Fig. 9 shows the TEM image of the Nano adsorbent. additionally, the morphology and binding of nanoparticles on the GO surface were confirmed using TEM analysis. The TEM image for GO offers a transparent and striped sheet structure with continuous aggregation. Meanwhile, the layered sheet of GO which enclosed the corrugated silk carbon-based sheets was observed. The TEM image of magnetic graphene oxide Nano adsorbent indicated a rough surface with highly occupied spherical grains. the supply of multiple groves was the key evidence for a powerful relationship between GO and iron oxide. No aggregation was observed to point the dispersion of Nano adsorbent [40].

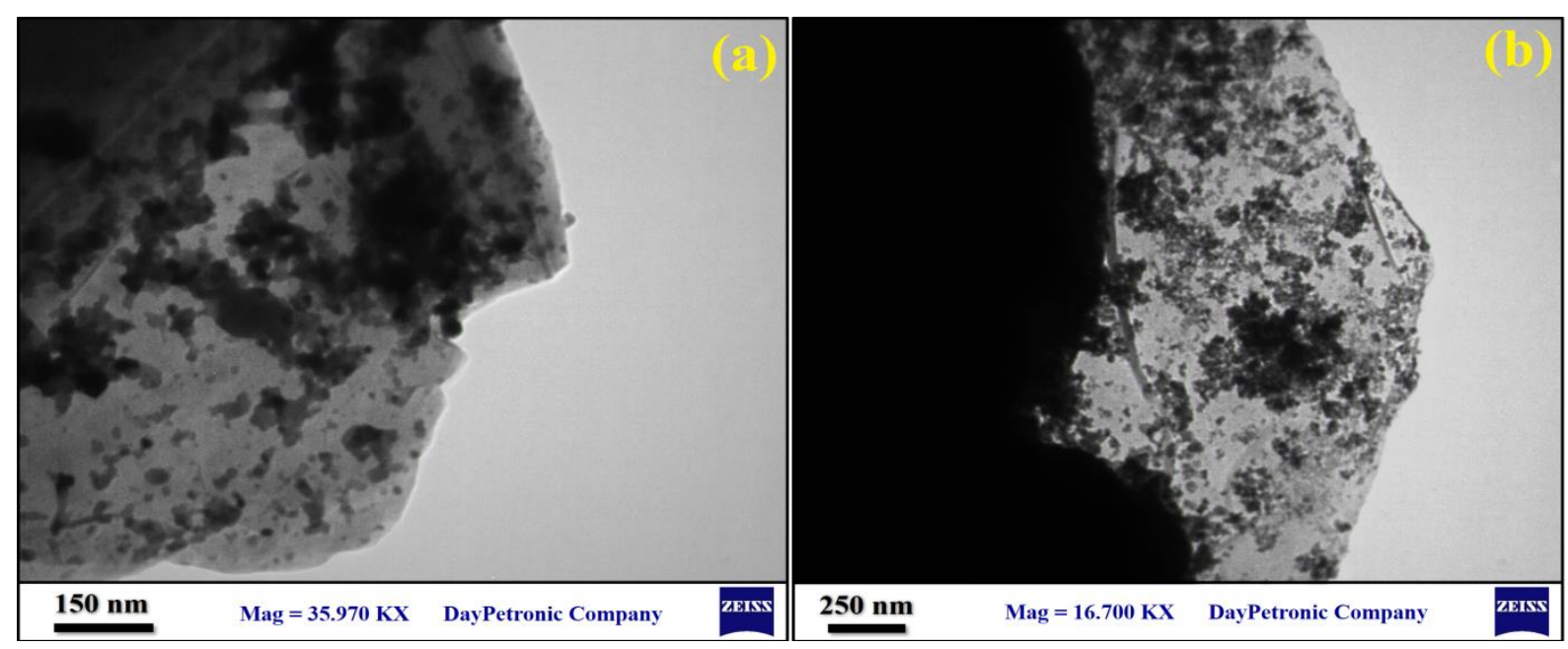

Fig. (9): Nano adsorbent TEM image with a magnification of a) $150 \mathrm{~nm}$ and b) $250 \mathrm{~nm}$ 


\subsection{Nano adsorbent surface charge}

$\mathrm{pH}_{\mathrm{pzc}}$ may be a parameter associated with the adsorption phenomenon which describes the conditions where the surface charge density equals zero. Fig. 10 indicates a very charge on the Nano adsorbent surface at $\mathrm{pH}$ but $\mathrm{pHpzc}$ and causes competitive adsorption between $\mathrm{H}+$ ions and cationic dye molecules within the solution. additionally, the amount of adsorption sites with charge increases with the reduction of $\mathrm{pH}$, leading to the desorption of cationic dye molecules electrostatically. However, the adsorption capacity increases significantly within the alkaline range $(\mathrm{pH}>\mathrm{pHpzc})$, which can result to the extrusion of surface functional groups which strongly adsorb the cationic fraction of MG molecules [41]. in step with Fig. 10, the adsorption of cationic dye on the adsorbent is more optimal at alkaline pHs of the dye solution. Thus, the worth of zero charge $(\Delta \mathrm{pH})$ is at $\mathrm{pHi}=7$ for the Nano adsorbent, being recorded because the zero charge point (pHpzc).

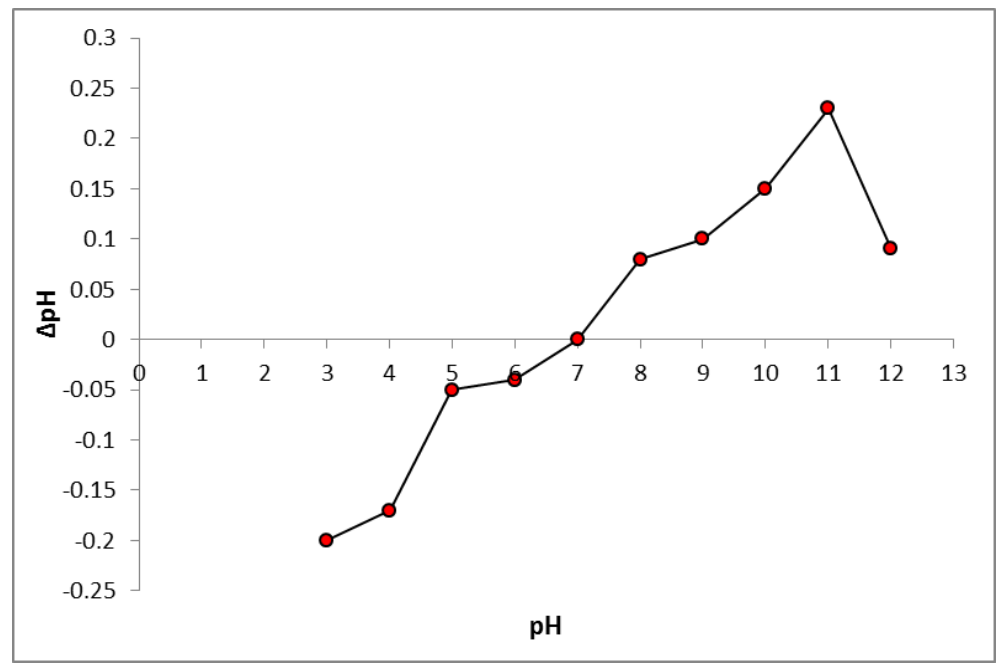

Fig. (10): Zero charge point of Nano adsorbent

\subsection{PH Effect}

Fig. 11 indicates the effect of $\mathrm{pH}$ on the adsorption capacity of malachite green dye by Nano adsorbent at $25{ }^{\circ} \mathrm{C}$, concentration $10 \mu \mathrm{gmL}-1$, and get in touch with time $60 \mathrm{~min}$. As may be observed, the very best adsorption rate for malachite dye was obtained at $\mathrm{pH}=8$. supported the results associated with the pHpzc parameter, the Nano adsorbent surface at $\mathrm{pH}>\mathrm{pHpzc}$ 
incorporates a charge. Thus, the electrostatic adsorption is made during this range between the anionized Nano adsorbent and cationic dyes and therefore the adsorption process is very strong at alkaline $\mathrm{pH}$.

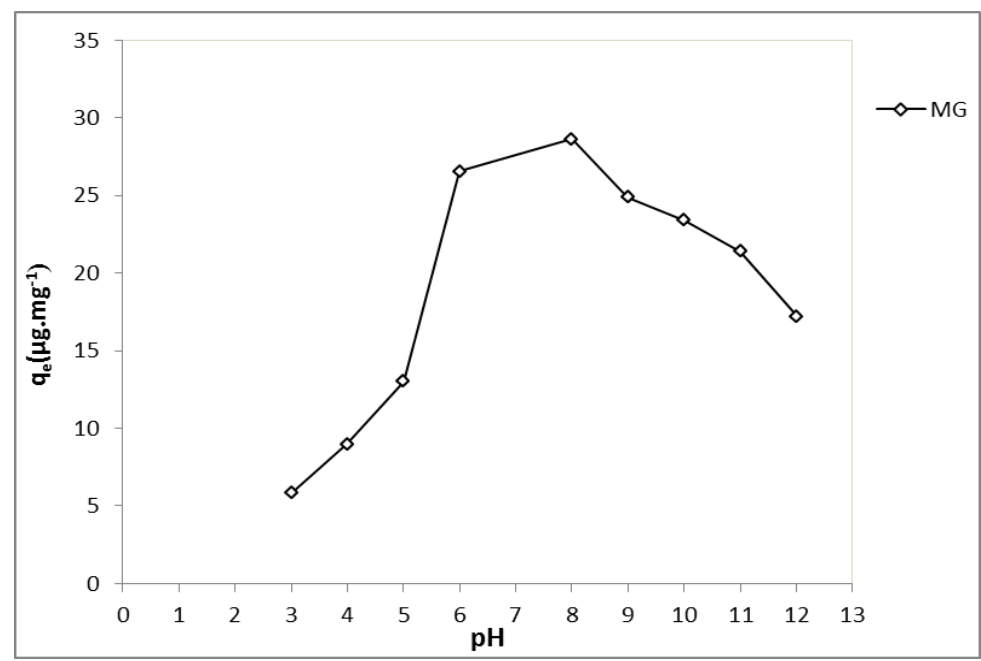

Fig. (11): Effect of $\mathrm{pH}$ on the adsorption rate of malachite green dye by Nano adsorbent at $25{ }^{\circ} \mathrm{C}$, concentration $10 \mu \mathrm{g} \mathrm{mL}^{-1}$ and contact time $60 \mathrm{~min}$

\subsection{Temperature effect}

Fig. 12 indicates the effect of temperature on the adsorption of malachite green dye by Nano adsorbent at an amount $10 \mu \mathrm{g} \mathrm{mL} \mathrm{m}^{-1}$, contact time $60 \mathrm{~min}$ and $\mathrm{pH}$. The results of the figures indicate that the optimal adsorption temperature for the adsorption process of malachite green dye with Nano adsorbent is $40^{\circ} \mathrm{C}$. As are often observed, the dye adsorption increases with increasing temperature from $25^{\circ} \mathrm{C}$ to $40{ }^{\circ} \mathrm{C}$.

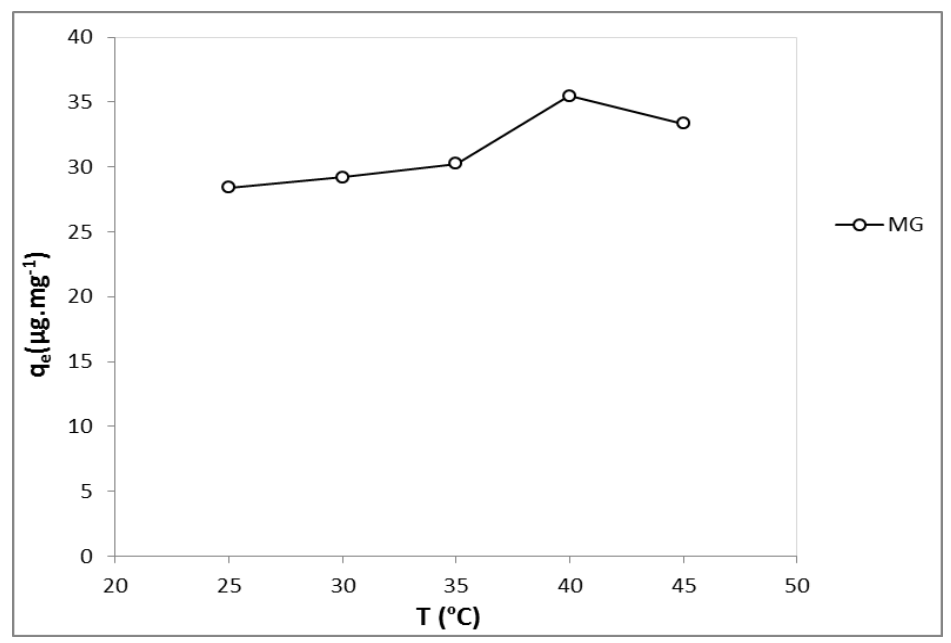


Fig. (12): Effect of temperature on the adsorption of malachite green by Nano adsorbent at a concentration of $10 \mu \mathrm{g} \mathrm{mL} \mathrm{m}^{-1}$, contact time $60 \mathrm{~min}$, and $\mathrm{pH} 8$

\subsection{Effect of dye concentration and study of adsorption isotherms}

Fig. (13) indicates the quantity of malachite green dye adsorption by Nano adsorbent at $\mathrm{pH} 8$, temperature $40{ }^{\circ} \mathrm{C}$, contact time $60 \mathrm{~min}$, and different concentrations of dye solution. As is observed, the synthesized Nano adsorbent can adsorb dye in numerous concentrations, but its amount is different at different concentrations. the utmost value of qe for malachite green dye at concentration $600 \mu \mathrm{g} \mathrm{mL}-1$ was adequate to $452.97 \mu \mathrm{g} \mathrm{mg}^{-1}$. This increasing trend will be explained that the quantity of surface active groups which might establish a bond between the dye and therefore the nanoparticle increases with increasing the concentration of the dye solution, resulting in more dye adsorption.

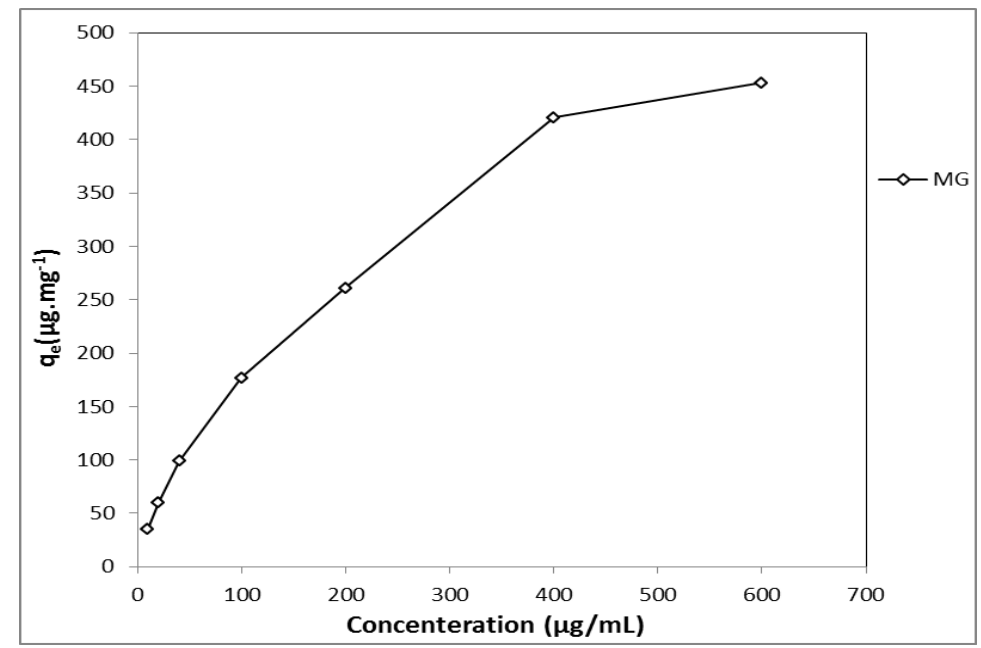

Fig. (13): Effect of dye concentration on the adsorption of malachite green by Nano adsorbent at $\mathrm{pH} 8$, temperature $40{ }^{\circ} \mathrm{C}$, and contact time $60 \mathrm{~min}$

Langmuir, Freundlich and Temkin isotherms were matched with laboratory data on dye adsorption at $\mathrm{pH}$ and optimal temperature at different concentrations. The parameters obtained from the fitting of the isotherms are given in Table 1 . A high correlation of upper than $\mathrm{R}^{2}$ for the Freundlich model confirms that the Freundlich model is acceptable for fitting laboratory data. 
The Freundlich model states that the heterogeneous Nano adsorbent surface is homogeneous and is obtained by non-uniform distribution of warmth adsorption on the surface. additionally, the worth of KF was 1.011, indicating that the desirable dye is adsorbed by the Nano adsorbent. On the opposite hand, it shows that the adsorption is desirable considering $1 / \mathrm{n}=0.591$ for malachite green. On the opposite hand, in step with the qmax value of Langmuir model for malachite green dye, it's capable $339.77 \mu$ gmg-1. Nevertheless, the Temkin model is more in keeping with experimental data compared to the Freundlich model. supported to the Temkin model, the adsorption heat for malachite green dye $\mathrm{B}=8.1447 \mathrm{jmol}^{-1}$, indicating that the method of dye adsorption with Nano adsorbent is of physical type. The Dubinin-Radushkevich isotherm model determines the properties of the adsorption process and free energy. supported the table, the worth of E obtained for the dyes (less than $8 \mathrm{kjmol}^{-1}$ ) shows that the method of dye adsorption is physical.

Table 1: Isotherm parameters for dye adsorption

\begin{tabular}{|c|c|c|}
\hline Isotherm model & Parameters & MG \\
\hline \multirow{4}{*}{ Langmuir } & $\mathrm{q}_{\mathrm{m}}\left(\mu \mathrm{g} \mathrm{mg}^{-1}\right)$ & 339.77 \\
\cline { 2 - 3 } & $\mathrm{K}_{\mathrm{L}}$ & 0.1927 \\
\cline { 2 - 3 } & $\mathrm{R}^{2}$ & 0.9874 \\
\hline \multirow{4}{*}{ Freundlich } & $\mathrm{K}_{\mathrm{F}}$ & 1.311 \\
\hline \multirow{4}{*}{ Temkin } & $1 / \mathrm{n}$ & 0.391 \\
\cline { 2 - 3 } & $\mathrm{R}^{2}$ & 0.9947 \\
\hline \multirow{4}{*}{ Dubinin-Radushkevich } & $\mathrm{A}$ & 17.273 \\
\cline { 2 - 3 } & $\mathrm{B}$ & 8.1447 \\
\cline { 2 - 3 } & $\mathrm{q}_{\mathrm{m}}\left(\mu \mathrm{R} \mathrm{mg}^{-1}\right)$ & 0.9307 \\
\cline { 2 - 3 } & ${\mathrm{C}\left(\mathrm{j} \mathrm{mol}^{2} \mathrm{~mol}^{-1}\right)}_{223.26}$ & $2 \times 10^{-5}$ \\
\cline { 2 - 3 } & $\mathrm{R}^{2}$ & 0.03535 \\
\hline
\end{tabular}

\subsection{Contact time Effect}

In order to research the effect of contact time on adsorption capacity, which is thought as kinetic studies, the adsorption of malachite green dye was investigated at $40^{\circ} \mathrm{C}, \mathrm{pH} 8$, initial concentration 
$600 \mu \mathrm{g} \mathrm{mL}^{-1}$ and $10 \mathrm{mg}$ of Nano adsorbent within the time range of 0.5-60 min. Fig. 14 indicates that the most adsorption of dye by the Nano adsorbent during the primary 10 minutes increased at a awfully high rate thanks to the empty or easy reaction sites on the external surface of the Nano adsorbent and therefore the increase of adsorption time. The adsorption of the dye was balanced in half-hour. Thus, it remained thanks to the reduced availability of remaining active sites. additionally, it requires longer for achieving equilibrium because of the long-term diffusion in Nano adsorbent micro pores [42].

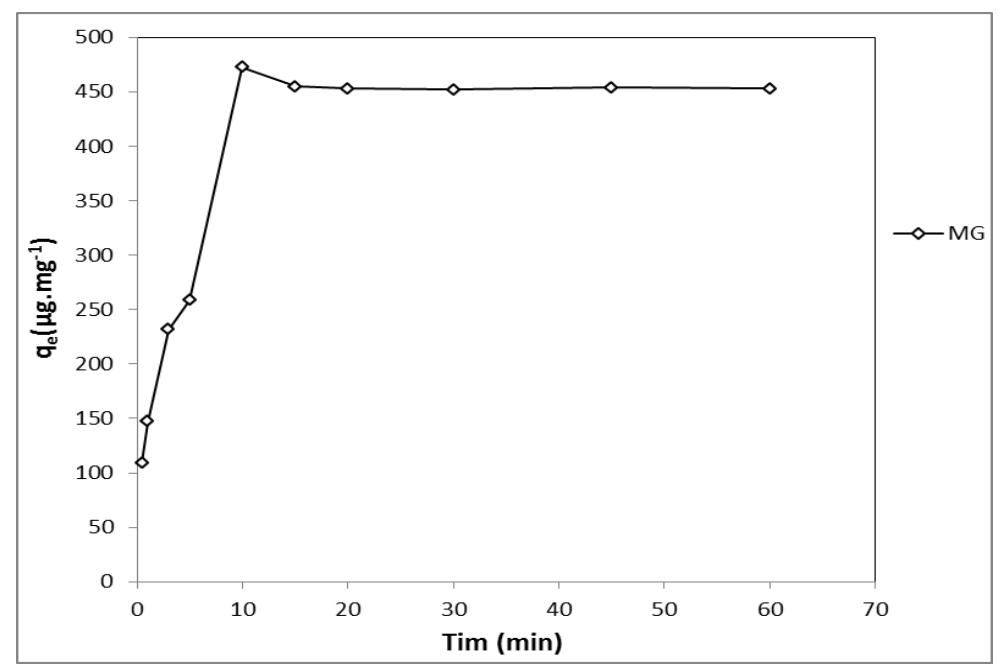

Fig. (14): The effect of time on the amount of dye adsorption

Based on the results obtained from fitting the dye adsorption kinetics models by Nano adsorbent, the $\mathrm{Hu}$ and McKay model with higher correlation coefficient $\left(\mathrm{R}^{2}=0.994\right)$ is more consistent with experimental data than the other models. The results obtained from fitting the synthetic models are given in Table 2.

Table (2): Adsorption kinetics parameters

\begin{tabular}{|c|c|c|}
\hline kinetic models & Parameters & MG \\
\hline \multirow{3}{*}{ Lagergren } & $\mathrm{q}_{\mathrm{e}}\left(\mu \mathrm{g} \mathrm{mg}^{-1}\right)$ & 350.14 \\
\cline { 2 - 3 } & $\mathrm{K}$ & 0.2266 \\
\cline { 2 - 3 } & $\mathrm{R}^{2}$ & 0.9522 \\
\hline \multirow{2}{*}{ Ho and McKay } & $\mathrm{qe}_{\mathrm{e}}\left(\mu \mathrm{g} \mathrm{mg}^{-1}\right)$ & 472.24 \\
\cline { 2 - 3 } & $\mathrm{K}$ & 0.1036 \\
\hline
\end{tabular}




\begin{tabular}{|c|c|c|}
\hline & $\mathrm{R}^{2}$ & 0.9963 \\
\hline \multirow{4}{*}{ Intraparticle diffusion } & $\mathrm{C}$ & 19.798 \\
\cline { 2 - 3 } & $\mathrm{K}$ & 4.8808 \\
\cline { 2 - 3 } & $\mathrm{R}^{2}$ & 0.6746 \\
\hline \multirow{3}{*}{ Elovich model } & $\mathrm{Q}$ & 0.2448 \\
\cline { 2 - 3 } & $\mathrm{P}$ & 230.28 \\
\cline { 2 - 3 } & $\mathrm{R}^{2}$ & 0.8694 \\
\hline
\end{tabular}

\subsection{Study of adsorption thermodynamics}

The thermodynamic study of dye adsorption was conducted at temperatures $25-45^{\circ} \mathrm{C}$. In such conditions, the distribution coefficient $(\mathrm{KD}=\mathrm{Ce} / \mathrm{qe})$ was calculated. Then, the enthalpy and entropy of adsorption were calculated using the slope of the road $(-\Delta H / R)$ and $y$-intercept $(\Delta S / R)$ of $\ln k D$ diagram versus $1 / \mathrm{T}$. The parameter values are presented in Table 3 . The results indicate that the values of $\Delta \mathrm{G}$ obtained from the study of thermodynamics are negative for dyes, showing that the character of the dye by Nano adsorbent is spontaneous.

Table (3): Results obtained from the study of adsorption thermodynamics

\begin{tabular}{|c|c|c|c|c|c|}
\hline $\begin{array}{c}\text { Temperature } \\
\left({ }^{\circ} \mathrm{C}\right)\end{array}$ & $\begin{array}{c}\mathbf{K}_{\mathbf{D}} \\
\left(\mathbf{m L} \mu \mathbf{g}^{-1}\right)\end{array}$ & Ln k & $\begin{array}{c}\Delta G \\
\left(\mathbf{k j ~ m o l}^{-1}\right)\end{array}$ & $\begin{array}{c}\Delta \mathbf{H} \\
\left(\mathrm{kj} \mathrm{mol}^{-1}\right)\end{array}$ & $\begin{array}{c}\Delta S \\
\left(\mathbf{j} \mathbf{~ m o l}^{-1} \mathbf{k}^{-1}\right)\end{array}$ \\
\hline 298 & 7.21 & 1.97 & -4.77 & -19.62 & -48.62 \\
\hline 303 & 6.62 & 1.89 & -4.64 & & \\
\hline 308 & 5.79 & 1.75 & -4.09 & & \\
\hline 313 & 5.16 & 1.64 & -3.69 & & \\
\hline 318 & 4.88 & 1.58 & -3.36 & & \\
\hline
\end{tabular}

\subsection{Adsorbent regeneration}

Fig. 15 shows the reusability of the adsorbent through successive dye adsorption cycles under optimal laboratory conditions at $\mathrm{pH} 8$, initial concentration $600 \mu \mathrm{g} \mathrm{mL}-1$, temperature $40{ }^{\circ} \mathrm{C}, 10$ $\mathrm{mg}$ and $10 \mathrm{~min}$. so as to get rid of the adsorbent dye, first it absolutely was taken out of the aqueous medium after the adsorption test so $20 \mathrm{ml}$ of hydrated oxide $(\mathrm{NaOH})$ solutions $0.05,0.1$ and 0.2 $\mathrm{M}$ and acid $(\mathrm{HCl})$ 0.05, 0.1 and $0.2 \mathrm{M}$ were added and stirred for quarter-hour. Then, the Nano sorbent was separated from the answer and also the adsorption capacity was calculated as 531, 
585, and $582 \mu \mathrm{g}$.gr ${ }^{-1}$ for $\mathrm{NaOH}$ of $0.05,0.1$ and $0.2 \mathrm{M}$ and 529, 595, and $512 \mu \mathrm{g} . \mathrm{gr}^{-1}$ for HCI 0.1M, respectively. As may be observed from these results, the utmost adsorption capacity was obtained using $0.1 \mathrm{M} \mathrm{HCl}$ solution consistent with the alkaline environment of the dye solution $(\mathrm{pH}=8)$ and thus was selected because the optimal detergent. After that, all of the steps were performed rather than $\mathrm{HCl}$ with $20 \mathrm{ml}$ water on the isolated Nano adsorbent [43].

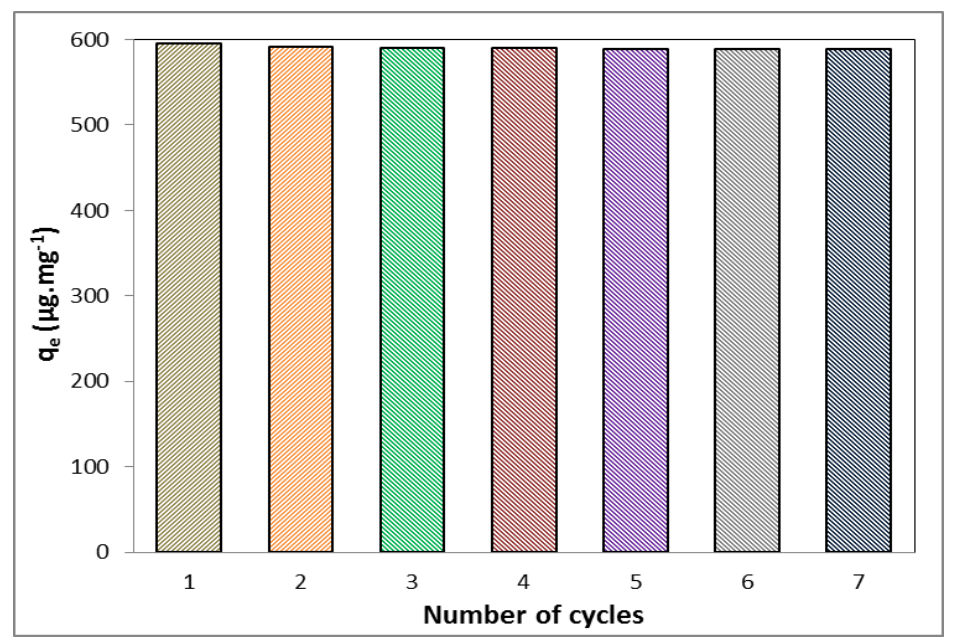

Fig. (15): Regeneration of adsorbent at $\mathrm{pH} 8$, initial concentration $600 \mu \mathrm{g} \mathrm{mL}{ }^{-1}$, temperature 40 ${ }^{\circ} \mathrm{C}, 10 \mathrm{mg}$ and $10 \mathrm{~min}$

\subsection{Comparison of some reported adsorbents for MG adsorption}

Various adsorbents are used for removing the MG dye from the solution. Table 4 presents the summary of the comparison between the adsorption rates of various adsorbents. Obviously, the proposed adsorbent (G (1) -MGO-chitosan) during this study has an especially high adsorption capacity compared to other reported adsorbents.

Table (4): Comparison of G(1) -MGO-chitosan adsorption capacity with other reported adsorbents

\begin{tabular}{|c|c|c|c|c|c|}
\hline Adsorbent & $\mathbf{p H}$ & $\begin{array}{c}\text { Tim } \\
(\mathbf{m i n})\end{array}$ & $\begin{array}{c}\text { Temperature } \\
\left({ }^{\circ} \mathbf{C}\right)\end{array}$ & $\begin{array}{c}\text { Adsorption capacity } \\
\mathbf{~} \mathbf{~ m g / g ~ ( ~}\end{array}$ & Ref . \\
\hline $\mathrm{G}(1)$-MGO-chitosan & 8 & 10 & 40 & 452.97 & This study \\
\hline $\mathrm{SnO}_{2}-\mathrm{NP}-\mathrm{AC}$ & 5 & 30 & 25 & 142.87 & {$[44]$} \\
\hline $\begin{array}{c}\text { chemically modified } \\
\text { cellulose by anhydride }\end{array}$ & 7 & 180 & 30 & 370 & {$[45]$} \\
\hline $\begin{array}{c}\text { multi-walled carbon } \\
\text { nanotubes (MWCNTs) }\end{array}$ & 8 & 10 & 35 & 62.11 & {$[46]$} \\
\hline $\mathrm{CoFe} \mathrm{O}_{4} \mathrm{SiO}_{2}$ & 6 & 70 & 25 & 75.5 & {$[47]$} \\
\hline $\mathrm{Cu}-\mathrm{MOF}_{2} / \mathrm{Fe}_{3} \mathrm{O}_{4}$ & 7 & 40 & 35 & 113.67 & {$[48]$} \\
\hline
\end{tabular}




\begin{tabular}{|c|c|c|c|c|c|}
\hline $\begin{array}{c}\text { boron doped mesoporous } \\
\text { carbon nitride (BMCN ( }\end{array}$ & 5 & 30 & 25 & 310 & {$[49]$} \\
\hline $\begin{array}{c}\text { Zeolitic Imidazolate } \\
\text { framework/graphene oxide } \\
\text { composites (ZIF-67@ GO) }\end{array}$ & 6 & 15 & 30 & 134.79 & {$[21]$} \\
\hline MOF & 8 & 50 & 25 & 198.1 & {$[50]$} \\
\hline $\begin{array}{c}\text { Graphene-Silver oxide } \\
\text { nanocomposite (GO-Ag) }\end{array}$ & 8 & 10 & 35 & 65.21 & {$[51]$} \\
\hline $\mathrm{Zn}(\mathrm{OH})_{2}$-AC composite & 7 & 30 & 45 & 303.3 & {$[52]$} \\
\hline $\mathrm{Fe}_{3} \mathrm{O}_{4} @$ chitosan@ZIF-8 & 7 & 40 & 25 & 3.282 & {$[53]$} \\
\hline
\end{tabular}

\section{Conclusion}

First, the magnetic graphene oxide was synthesized by co-precipitation method and graphene oxide was aminoized by amidation reaction within the presence of ethylene diamine. Then, the unconventional polymerization process was performed on for allylamine alcohol and at the moment, chitosan was attached to allylamine by Michael reaction. so as to confirm the formation of synthesized Nano adsorbent and therefore the presence of factor groups, infrared spectroscopy (FTIR) was used. The structure and morphology of the Nano carriers were evaluated employing a transmission microscope (TEM). the utmost adsorption was obtained for malachite green dye at $\mathrm{pH}=8$. High coefficient of correlation $\left(\mathrm{R}^{2}=0.9947\right)$ for the Freundlich model confirms that this model is suitable for fitting laboratory data. The Freundlich model states that the heterogeneous Nano adsorbent surface is homogeneous and is obtained by non-uniform distribution of adsorption heat on the surface. supported the Temkin model, the adsorption heat for malachite green is $\mathrm{B}=8.1447 \mathrm{jmol}-1$ and shows that the method of dye adsorption with Nano adsorbent is physical. in step with the results obtained from fitting the models of dye adsorption kinetics by nanoadsorbent indicates that the $\mathrm{Hu}$ and McKay model with higher parametric statistic $(\mathrm{R} 2=0.9994)$ is more according to experimental data than other models. The values of $\Delta \mathrm{G}$ obtained from the study of thermodynamics are negative for the dye, indicating that the character of the dye by Nano adsorbent is spontaneous.

\section{Ethics approval and consent to participate}


I wrote to you in regard to your question about naming some people in my article, I must point out that in some cases, help was sought from people and it was necessary to mention the names of these people in order to maintain professional ethics in research issues.

Therefore, on this basis؛

Seyyed Ali Razavikia, Mehdi Faramarzi , Seyed Aboutaleb Mousavi Parsa, Hajir Karimi: Investigation, concept and design, experimental studies, Writing - original draft, reviewing and editing.

\section{Consent for publication}

Not applicable

\section{Availability of data and materials}

All data generated or analyzed during this study are included in this published article.

\section{Competing interests}

The author declare that they have no competing interests.

\section{Funding}

Not applicable

\section{Author information}

Seyyed Ali Razavikia, Mehdi Faramarzi, Seyed Aboutaleb Mousavi Parsa, Hajir Karimi.

\section{Acknowledgment}

This study is the result of work at Islamic Azad University, Yasouj Branch.

\section{References}

[1] Yin, G., Sun, Z., Gao, Y., \& Xu, S. (2021). Preparation of expanded graphite for malachite green dye removal from aqueous solution. Microchemical Journal, 166, 106190.

[2] Wang, Y., Yao, M., Chen, Y., Zuo, Y., Zhang, X., \& Cui, L. (2015). General synthesis of magnetic mesoporous FeNi/graphitic carbon nanocomposites and their application for dye adsorption. Journal of Alloys and Compounds, 627, 7-12. 
[3] Nazir, M. A., Bashir, M. A., Najam, T., Javed, M. S., Suleman, S., Hussain, S., ... \& ur Rehman, A. (2021). Combining structurally ordered intermetallic nodes: Kinetic and isothermal studies for removal of malachite green and methyl orange with mechanistic aspects. Microchemical Journal, 164, 105973.

[4] Khan, T. A., \& Khan, E. A. (2015). Removal of basic dyes from aqueous solution by adsorption onto binary iron-manganese oxide coated kaolinite: non-linear isotherm and kinetics modeling. Applied Clay Science, 107, 70-77.

[5] Sudova, E., Machova, J., Svobodova, Z., \& Vesely, T. (2007). Negative effects of malachite green and possibilities of its replacement in the treatment of fish eggs and fish: a review. Veterinarni medicina, 52(12), 527.

[6] Gopinathan, R., Kanhere, J., \& Banerjee, J. (2015). Effect of malachite green toxicity on non target soil organisms. Chemosphere, 120, 637-644.

[7] Ali, F., Bibi, S., Ali, N., Ali, Z., Said, A., Wahab, Z. U., ... \& Iqbal, H. M. (2020). Sorptive Removal of Malachite Green Dye by Activated Charcoal: Process Optimization, Kinetic, and Thermodynamic Evaluation. Case Studies in Chemical and Environmental Engineering, 100025.

[8] Sreedharan, A., \& Ong, S. T. (2020). Combination of Plackett Burman and response surface methodology experimental design to optimize Malachite Green dye removal from aqueous environment. Chemical Data Collections, 25, 100317.

[9] Gündüz, F., \& Bayrak, B. (2017). Biosorption of malachite green from an aqueous solution using pomegranate peel: equilibrium modelling, kinetic and thermodynamic studies. Journal of Molecular Liquids, 243, 790-798.

[10] Elsehly, E. M., Chechenin, N. G., Makunin, A. V., Motaweh, H. A., Vorobyeva, E. A., Bukunov, K. A., Leksina, E. G. andPriselkova, A. B. (2016). Characterization of functionalized multiwalled carbon nanotubes and application as an effective filter for heavy metal removal from aqueous solutions. Chin. J. Chem. Eng., 24(12), 1695-1702.

[11] Mqehe-Nedzivhe, K. C., Makhado, K., Olorundare, O. F., Arotiba, O. A., Makhatha, E., Nomngongo, P. N. andMabuba, N. (2018). Bio-adsorbents for the Removal of Heavy Metals from Water. In Arsenic -Analytical and Toxicological Studies, 26-37, IntechOpen.

[12] Ghiloufi, I., Ghoul, J. El, Modwi, A. andMir, L. El. (2016). Ga-doped ZnO for adsorption of heavy metals from aqueous solution. Mater. Sci. Semicond. Process., 42, 102-106.

[13] Lafi, R., Montasser, I., \& Hafiane, A. (2019). Adsorption of congo red dye from aqueous solutions by prepared activated carbon with oxygen-containing functional groups and its regeneration. Adsorption Science \& Technology, 37(1-2), 160-181.

[14] Azizian, S., Eris, S. andWilson, L. D. (2018). Re-evaluation of the century-old Langmuir isotherm for modeling adsorption phenomena in solution. Chem. Phys., 513, 99-104.

[15] Banerjee, S., \& Chattopadhyaya, M. C. (2017). Adsorption characteristics for the removal of a toxic dye, tartrazine from aqueous solutions by a low cost agricultural by-product. Arabian Journal of Chemistry, 10, S1629-S1638.

[16] Saleh, T. A., \& Gupta, V. K. (2014). Processing methods, characteristics and adsorption behavior of tire derived carbons: a review. Advances in colloid and interface science, 211, 93-101.

[17] Bankole, M. T., Abdulkareem, A. S., Mohammed, I. A., Ochigbo, S. S., Tijani, J. O., Abubakre, O. K. andRoos, W. D. (2019). Selected Heavy Metals Removal From Electroplating Wastewater by Purified and Polyhydroxylbutyrate Functionalized Carbon Nanotubes Adsorbents. Sci. Rep, 9(1), $1-19$. 
[18] Mohd, A. A., \& Rasyidah, A. (2011). Removal of malachite green dye from aqueous solution using rambutan peel-base activated carbon: Equilibrium, kinetic and thermodynamic studies. Chem. Engr. Journal, 171, 510-516.

[19] Roosta, M., Ghaedi, M., Daneshfar, A., Sahraei, R., \& Asghari, A. (2014). Optimization of the ultrasonic assisted removal of methylene blue by gold nanoparticles loaded on activated carbon using experimental design methodology. Ultrasonics sonochemistry, 21(1), 242-252.

[20] Hoijang, S., Wangkarn, S., Ieamviteevanich, P., Pinitsoontorn, S., Ananta, S., Lee, T. R., \& Srisombat, L. (2020). Silica-coated magnesium ferrite nanoadsorbent for selective removal of methylene blue. Colloids and Surfaces A: Physicochemical and Engineering Aspects, 606, 125483.

[21] Shah, H. U. R., Ahmad, K., Naseem, H. A., Parveen, S., Ashfaq, M., Rauf, A., \& Aziz, T. (2021). Water Stable Graphene Oxide Metal-Organic Frameworks Composite (ZIF-67@ GO) For Efficient Removal of Malachite Green From Water. Food and Chemical Toxicology, 112312.

[22] Dehghani, M. H., Tajik, S., Panahi, A., Khezri, M., Zarei, A., Heidarinejad, Z., \& Yousefi, M. (2018). Adsorptive removal of noxious cadmium from aqueous solutions using poly urea-formaldehyde: a novel polymer adsorbent. MethodsX, 5, 1148-1155.

[23] Nechifor, G., Pascu, D. E., Pascu, M., Traistaru, G. A., \& Albu, P. C. (2015). Comparative study of Temkin and Flory-huggins isotherms for adsorption of phosphate anion on membranes. Sci Bull B [Internet], 77(2), 63-72.

[24] Dubinin, M. (1960). The potential theory of adsorption of gases and vapors for adsorbents with energetically nonuniform surfaces. Chemical Reviews, 60(2), 235-241.

[25] Radushkevich, L. V. (1949). Potential theory of sorption and structure of carbons. Zhurnal Fizicheskoi Khimii, 23(12), 1410-1420.

[26] Kundu, S., \& Gupta, A. K. (2006). Investigations on the adsorption efficiency of iron oxide coated cement (IOCC) towards As (V) — kinetics, equilibrium and thermodynamic studies. Colloids and Surfaces A: Physicochemical and Engineering Aspects, 273(1-3), 121-128.

[27] Lagergren, S. K. (1898). About the theory of so-called adsorption of soluble substances. Sven. Vetenskapsakad. Handingarl, 24, 1-39.

[28] McKay, G. (2001). Solution to the homogeneous surface diffusion model for batch adsorption systems using orthogonal collocation. Chemical Engineering Journal, 81(1-3), 213-221.

[29] Ho, Y. S., \& McKay, G. (2000). The kinetics of sorption of divalent metal ions onto sphagnum moss peat. Water research, 34(3), 735-742.

[30] Shen, H., Wang, Z., Zhou, A., Chen, J., Hu, M., Dong, X., \& Xia, Q. (2015). Adsorption of phosphate onto amine functionalized nano-sized magnetic polymer adsorbents: mechanism and magnetic effects. RSC Advances, 5(28), 22080-22090.

[31] Zhang, Y., Wang, H., Eberhardt, T. L., Gu, Q., \& Pan, H. (2021). Preparation of carboxylated ligninbased epoxy resin with excellent mechanical properties. European Polymer Journal, 150, 110389.

[32] Chowdhury, S., \& Balasubramanian, R. (2014). Recent advances in the use of graphene-family nanoadsorbents for removal of toxic pollutants from wastewater. Advances in colloid and interface science, 204, 35-56.

[33] Periakaruppan, R., Chen, X., Thangaraj, K., Jeyaraj, A., Nguyen, H. H., Yu, Y., ... \& Li, X. (2021). Utilization of tea resources with the production of superparamagnetic biogenic iron oxide nanoparticles and an assessment of their antioxidant activities. Journal of Cleaner Production, 278, 123962. 
[34] Gibson, N., Kuchenbecker, P., Rasmussen, K., Hodoroaba, V. D., \& Rauscher, H. (2020). Volumespecific surface area by gas adsorption analysis with the BET method. In Characterization of Nanoparticles (pp. 265-294). Elsevier.

[35] Qi, L., Tang, X., Wang, Z., \& Peng, X. (2017). Pore characterization of different types of coal from coal and gas outburst disaster sites using low temperature nitrogen adsorption approach. International Journal of Mining Science and Technology, 27(2), 371-377.

[36]Asadi-Sangachini, Z., Galangash, M. M., Younesi, H., \& Nowrouzi, M. (2019). The feasibility of costeffective manufacturing activated carbon derived from walnut shells for large-scale $\mathrm{CO}_{2}$ capture. Environmental Science and Pollution Research, 26(26), 26542-26552.

[37] Biswas, A., Vanlalveni, C., Lalfakzuala, R., Nath, S., \& Rokhum, L. (2021). Mikania mikrantha leaf extract mediated biogenic synthesis of magnetic iron oxide nanoparticles: Characterization and its antimicrobial activity study. Materials Today: Proceedings, 42, 1366-1373.

[38] Zhu, Y., Xue, J., Xu, T., He, G., \& Chen, H. (2017). Enhanced photocatalytic activity of magnetic core-shell $\mathrm{Fe}_{3} \mathrm{O}_{4} @ \mathrm{Bi}_{2} \mathrm{O}_{3}-\mathrm{RGO}$ heterojunctions for quinolone antibiotics degradation under visible light. Journal of Materials Science: Materials in Electronics, 28(12), 8519-8528.

[39] Mashkoor, F., \& Nasar, A. (2021). Magnetized Chitosan Nanocomposite as an Effective Adsorbent for the Removal of Methylene Blue and Malachite Green Dyes.

[40] Ciğeroğlu, Z., Küçükyıldız, G., Erim, B., \& Alp, E. (2021). Easy preparation of magnetic nanoparticles-rGO-chitosan composite beads: Optimization study on cefixime removal based on RSM and ANN by using Genetic Algorithm Approach. Journal of Molecular Structure, 1224, 129182.

[41] Parvin, N., Babapoor, A., Nematollahzadeh, A., \& Mousavi, S. M. (2020). Removal of phenol and $\beta$ naphthol from aqueous solution by decorated graphene oxide with magnetic iron for modified polyrhodanine as nanocomposite adsorbents: Kinetic, equilibrium and thermodynamic studies. Reactive and Functional Polymers, 156, 104718.

[42] Du, Q., Sun, J., Li, Y., Yang, X., Wang, X., Wang, Z., \& Xia, L. (2014). Highly enhanced adsorption of congo red onto graphene oxide/chitosan fibers by wet-chemical etching off silica nanoparticles. Chemical Engineering Journal, 245, 99-106.

[43] Sadat, S. A., Ghaedi, A. M., Panahimehr, M., Baneshi, M. M., Vafaei, A., \& Ansarizadeh, M. (2019). Rapid room-temperature synthesis of cadmium zeolitic imidazolate framework nanoparticles based on 1, 1'-carbonyldiimidazole as ultra-high-efficiency adsorbent for ultrasound-assisted removal of malachite green dye. Applied Surface Science, 467, 1204-1212.

[44] Shamsizadeh, A., Ghaedi, M., Ansari, A., Azizian, S., \& Purkait, M. K. (2014). Tin oxide nanoparticle loaded on activated carbon as new adsorbent for efficient removal of malachite green-oxalate: non-linear kinetics and isotherm study. Journal of Molecular Liquids, 195, 212-218.

[45] Zhou, Y., Min, Y., Qiao, H., Huang, Q., Wang, E., \& Ma, T. (2015). Improved removal of malachite green from aqueous solution using chemically modified cellulose by anhydride. International journal of biological macromolecules, 74, 271-277.

[46] Ghaedi, M., Dashtian, K., Ghaedi, A. M., \& Dehghanian, N. (2016). A hybrid model of support vector regression with genetic algorithm for forecasting adsorption of malachite green onto multi-walled carbon nanotubes: central composite design optimization. Physical Chemistry Chemical Physics, 18(19), 1331013321.

[47] Amiri, M., Salavati-Niasari, M., Akbari, A., \& Gholami, T. (2017). Removal of malachite green (a toxic dye) from water by cobalt ferrite silica magnetic nanocomposite: herbal and green sol-gel autocombustion synthesis. international journal of hydrogen energy, 42(39), 24846-24860. 
[48] Shi, Z., Xu, C., Guan, H., Li, L., Fan, L., Wang, Y., ... \& Zhang, R. (2018). Magnetic metal organic frameworks (MOFs) composite for removal of lead and malachite green in wastewater. Colloids and Surfaces A: Physicochemical and Engineering Aspects, 539, 382-390.

[49] Azimi, E. B., Badiei, A., \& Ghasemi, J. B. (2019). Efficient removal of malachite green from wastewater by using boron-doped mesoporous carbon nitride. Applied Surface Science, 469, 236-245.

[50] Li, A., Xiong, J., Liu, Y., Wang, L., Qin, X., \& Yu, J. (2021). Fiber-intercepting-particle structured MOF fabrics for simultaneous solar vapor generation and organic pollutant adsorption. Chemical Engineering Journal, 131365.

[51] Ahmad, A., Setapar, S. H. M., Yaqoob, A. A., \& Ibrahim, M. N. M. (2021). Synthesis and characterization of GO-Ag nanocomposite for removal of malachite dye from aqueous solution. Materials Today: Proceedings.

[52] Altıntıg, E., Yenigun, M., Sarı, A., Altundag, H., Tuzen, M., \& Saleh, T. A. (2021). Facile synthesis of zinc oxide nanoparticles loaded activated carbon as an eco-friendly adsorbent for ultra-removal of malachite green from water. Environmental Technology \& Innovation, 21, 101305.

[53] Zadvarzi, S. B., Khavarpour, M., Vahdat, S. M., Baghbanian, S. M., \& Rad, A. S. (2021). Synthesis of Fe3O4@ chitosan@ ZIF-8 towards removal of malachite green from aqueous solution: Theoretical and experimental studies. International Journal of Biological Macromolecules, 168, 428-441. 